\title{
Limited SHIV env diversification in macaques failing oral antiretroviral pre-exposure prophylaxis
}

\author{
Qi Zheng, Susan Ruone, William M Switzer, Walid Heneine and J Gerardo García-Lerma*
}

\begin{abstract}
Background: Pre-exposure prophylaxis (PrEP) with daily Truvada [a combination of emtricitabine (FTC) and tenofovir disoproxil fumarate (TDF)] is a novel HIV prevention strategy recently found to prevent HIV transmission among men who have sex with men and heterosexual couples. Acute infection in adherent persons who fail PrEP will inevitably occur under concurrent antiretroviral therapy, thus raising questions regarding the potential impact of PrEP on early viral dynamics. We investigated viral evolution dynamics in a macaque model of PrEP consisting of repeated rectal exposures to $\mathrm{SHIV}_{162 \mathrm{P} 3}$ in the presence of PrEP.

Results: Four macaques were infected during daily or intermittent PrEP with FTC or FTC/TDF, and five were untreated controls. SHIV env sequence evolution was monitored by single genome amplification with phylogenetic and sequence analysis. Mean nucleotide divergence from transmitted founder viruses calculated 17 weeks (range $=12-20$ ) post peak viremia was significantly lower in PrEP failures than in control animals $\left(7.2 \times 10^{-3}\right.$ compared to $1.6 \times 10^{-2}$ nucleotide substitutions per site per year, respectively, $p<0.0001)$. Mean virus diversity was also lower in PrEP failures after 17 weeks ( $0.13 \%$ vs. $0.53 \%$ in controls, $p<0.0001)$.

Conclusions: Our results in a macaque model of acute HIV infection suggest that infection during PrEP limits early virus evolution likely because of a direct antiviral effect of PrEP and/or reduced target cell availability. Reduced virus diversification during early infection might enhance immune control by slowing the selection of escape mutants.
\end{abstract}

Keywords: Single genome amplification, Pre-exposure prophylaxis, Emtricitabine, Truvada

\section{Background}

Oral administration of antiretroviral (ARV) drugs before exposure to HIV (pre-exposure prophylaxis [PrEP]) is a novel prevention strategy to protect high-risk HIV-1-negative people from becoming infected [1]. Two recently completed trials with daily Truvada (a combination of emtricitabine $[\mathrm{FTC}]$ and tenofovir disoproxil fumarate [TDF]) have provided the first indication that oral PrEP reduces HIV transmission $[2,3]$. In these trials, the incidence of HIV-1 was reduced by $44 \%$ among men who have sex with men (MSM) and $62.6 \%$ among heterosexual couples; efficacy was substantially higher for study participants who reported high adherence or were on study medication $[2,3]$. An additional clinical trial among serodiscordant couples recently discontinued the placebo arm due to the strong HIV prevention effect seen by TDF (62\% fewer infections) and

\footnotetext{
* Correspondence: GGarcia-Lerma@cdc.gov Laboratory Branch, Division of HIV/AIDS Prevention, National Center for HIV, Hepatitis, STD, and Prevention, Centers for Disease Control and Prevention, Atlanta, GA, USA
}

(c) 2012 Zheng et al.; licensee BioMed Central Ltd. This is an Open Access article distributed under the terms of the Creative Commons Attribution License (http://creativecommons.org/licenses/by/2.0), which permits unrestricted use, distribution, and reproduction in any medium, provided the original work is properly cited.

Truvada (73\% fewer infections) [4]. A fourth trial (FEMPrEP) with Truvada among high-risk women was recently stopped due to futility as a result of low adherence.

Since current PrEP regimens are not 100\% protective, it is essential to understand the characteristics of acute infections that occur during PrEP use in humans. In contrast to natural HIV infections that are characterized by the absence of selective pressures prior to the development of acquired immune responses, early replication and systemic dissemination during infections that occur during PrEP can face an increased genetic bottleneck due to ARV drug activity. Strong drug selective pressures have the potential to shape early virus evolution and diversification from transmitted/founder viruses and alter host immune responses. Infection of non-human primates with SHIV can be used to model how PrEP influences early viral and immunological parameters. This model can recapitulate human infection by using R5-tropic isolates and low challenge doses that better mimic the transmission dynamics of HIV infection [5]. We recently found that 
macaques infected with $\mathrm{SHIV}_{162 \mathrm{P} 3}$ during prophylactic treatment with FTC or Truvada had lower peak viremias and a more rapid decline of virus loads to set-point levels compared to untreated animals, likely due to continued antiretroviral drug treatment during acute infection [6-8]. Interestingly, macaques infected during PrEP had altered acute immune parameters including delayed maturation of antibody avidity against multiple structural and functional antigens, reduced inflammatory responses, and minimal early CD4+ $\mathrm{T}$ cell losses [6-10]. While these unique immune parameters likely reflected reduced virus replication under PrEP, they also raised questions about the dynamics of the virus population during acute infection.

The study of early HIV and SIV sequences by singlegenome amplification (SGA) provides an accurate picture of the characteristics of transmitted/founder HIV and SIV variants and the distribution of viral quasispecies during primary infection [11,12]. In the absence of adaptive immune pressure or other selective pressures, virus diversification shortly after infection follows a pattern of random evolution with an almost star like phylogeny and a Poisson distribution of nucleotide substitutions [13]. Here we use SGA and sequence analysis to assess the impact of antiretroviral drugs during PrEP failure on viral dynamics. We demonstrate that PrEP confers a severe bottleneck that significantly slows early virus evolution and diversification. These findings in macaques highlight the need to better understand the impact of PrEP on acute HIV infection and the natural course of disease in humans.

\section{Results}

Dynamics of acute viral infection in treated and untreated macaques

Figure 1 shows the kinetics of virus replication and seroconversion in the nine treated and untreated SHIVinfected macaques. Peak viremias in untreated control macaques AG94, AI22, AO86, AM20, and $17 \mathrm{~V}$ were 7.3, 7.8, 7.7, 7.6, and $8.2 \log _{10}$ RNA copies/ml, respectively. Peak viremias in the two daily FTC (4.3 and 5.6 $\log _{10}$ copies $/ \mathrm{ml}$ ) and the two intermittent Truvada failures (5.8 and $6.1 \log _{10}$ copies $/ \mathrm{ml}$ ) were lower, consistent with the generally blunted acute viremias seen in macaques infected during PrEP in previous studies [6-8] (Figure 1). Macaques AG80 and AG46 received daily FTC for 29 and 24 weeks after the first detectable SHIV RNA in plasma, respectively; AG46 developed the M184V mutation associated with FTC resistance 11 weeks after infection (Figure 1; red dots). The frequency of M184V-containing mutants determined by sensitive real-time PCR was low (16-20\%) at week 11, below the assay cutoff $(0.6 \%)$ at week 12 , and high (100\%) 22 weeks after infection (not shown) [8]. Macaques DK40 and DL6V also continued receiving two weekly doses of Truvada for 19 and 14 weeks after infection, respectively (Figure 1). Neither of these two macaques had detectable mutations associated with FTC (M184V) or tenofovir (TFV) (K65R) resistance (not shown), despite the long intracellular half-life of FTCtriphosphate and TFV-diphosphate [7,8]. All animals seroconverted within 2-5 weeks after the first detection of RNA in plasma (Figure 1).

\section{Viral diversity in the SHIV 162P3 virus stock and in control untreated SHIV 162P3 $_{\text {infections }}$}

Twenty-three env nucleotide sequences were generated by SGA for the $\mathrm{SHIV}_{162 \mathrm{P} 3}$ stock. Consistent with the limited heterogeneity of the $\operatorname{SHIV}_{162 \mathrm{P} 3}$ virus stock $[14,15]$, the overall nucleotide diversity was found to be low (mean $=0.09 \%$; $\min , \max =0-0.5 \%$ ) (Figure 2).

We generated 326 env sequences from plasma by SGA in the five untreated control macaques infected rectally with SHIV $_{162 \mathrm{P} 3}$. The specific time points used for SGA analysis are denoted as green dots in Figure 1 and are referred as weeks after peak viremia. Of the 326 env sequences, 88 were obtained from macaque AI22 (30 at peak viremia, 24 after 16 weeks, and 34 after 24 weeks), 72 from macaque AG94 (23 at peak viremia, 21 after 19 weeks, and 28 after 26 weeks), 48 from macaque AO86 (28 at peak viremia and 20 after 20 weeks), 37 from macaque AM20 (20 at peak viremia and 17 after 18 weeks), and 81 from macaque $17 \mathrm{~V}$ (27 at peak viremia, 31 at week 12 , and 25 at week 25). Figure 3 shows the neighbor-joining tree and Highlighter plots generated with env sequences from these macaques and demonstrate that all 5 animals were infected by a single variant as indicated by the limited number of env sequences seen at peak viremia [16].

We next calculated the genetic diversity of env sequences obtained from longitudinal plasma specimens collected at several time points after infection. Mean env diversity in control macaque AI22 at peak viremia was $0.02 \%$ ( $\mathrm{min}$, $\max =0-0.3$ ) and increased to $0.72 \%$ after 16 ( $\min , \max =$ $0-1.6$ ) and 24 weeks ( $\min , \max =0-1.7$ ). Similarly, mean env diversity in control macaque AG94 was $0.1 \%$ (min, $\max =0-0.40)$ at peak viremia, $0.92 \%(\min , \max =0.1-1.9)$ after 19 weeks, and $0.96 \%$ ( $\min , \max =0-1.9)$ after 26 weeks. For macaques AO86, AM20, and $17 \mathrm{~V}$, mean env diversity at peak viremia was $0.07 \%(\min , \max =0,0.4)$, $0.04 \%$ ( $\min , \max =0,0.3$ ) and $0.04 \%(\min , \max =0,0.3$ ), respectively. Diversity increased in macaques AM20 ( mean $=0.43 \%$; $\min , \max =0-1.0)$ and $17 \mathrm{~V}$ (mean $=0.47$; $\min , \max =0,1.1$ ) after 18 and 12 weeks, respectively, and remained low in macaque A086 after 20 weeks (mean = 0,08 ; $\min , \max =0-0.3$ ). Figure 4 shows the increasing env nucleotide divergence from transmitted founder viruses seen in 4 of the 5 control macaques over time. Mean nucleotide substitutions per site per year in these macaques 


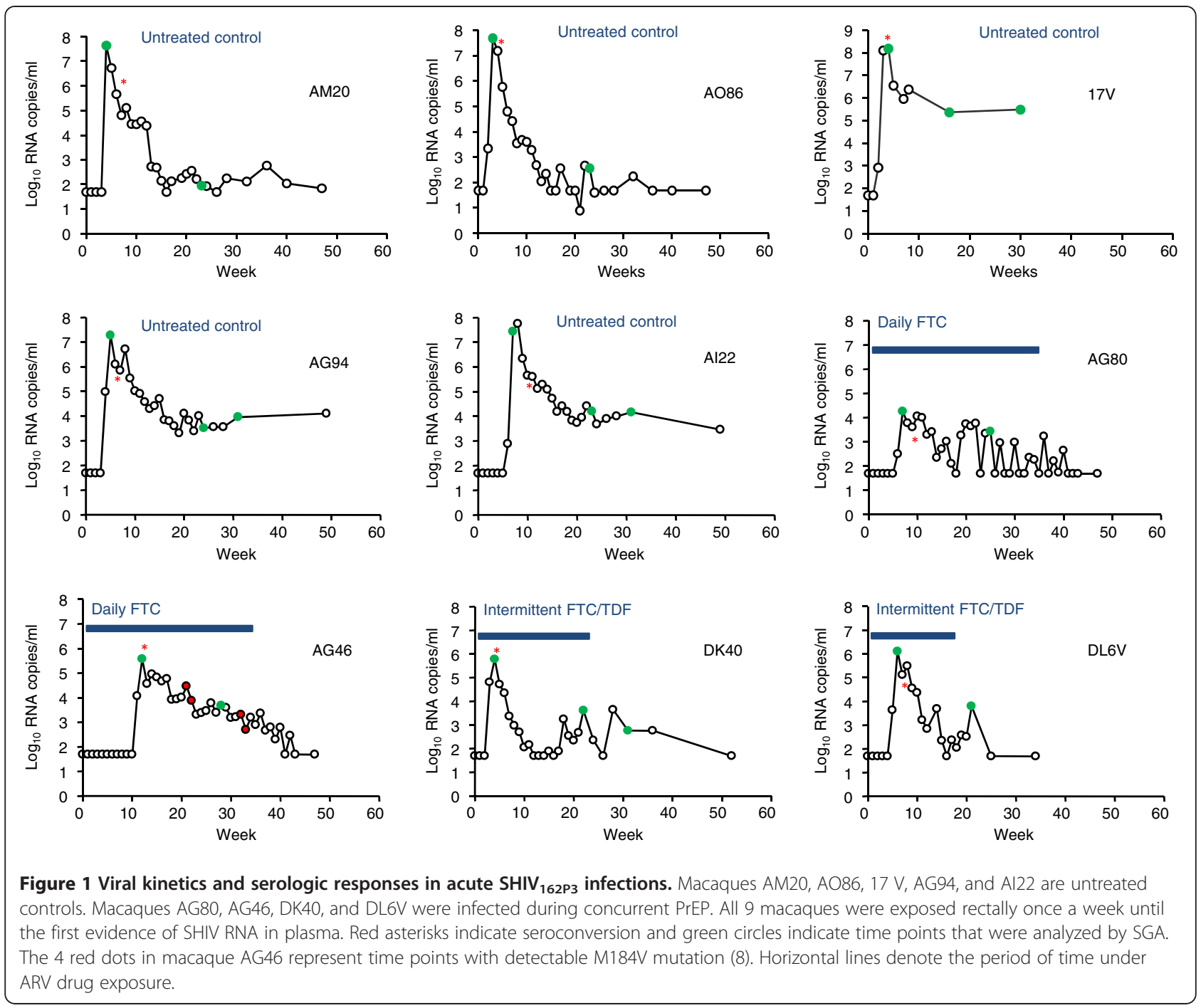

were $1.6 \times 10^{-2}$ and ranged from $3.7 \times 10^{-3}$ in AO86 to $3.0 \times 10^{-2}$ in AG94.

\section{Limited viral diversity in SHIV 162 $_{163}$-infected macaques failing daily or intermittent PrEP with FTC or Truvada}

We next explored the degree of viral diversity in the four macaques infected with SHIV $_{162 \mathrm{P} 3}$ during daily or intermittent PrEP. Figure 5 shows the neighbor-joining tree and Highlighter plots in these four PrEP breakthrough animals showing the limited viral env diversity in these animals. Mean env nucleotide diversity in macaques AG80 and AG46 that failed daily FTC was low both at peak viremia and after 16 to 18 weeks of follow up. In these two animals, the overall env diversity at peak viremia was $0.015 \%$ ( $\min , \max =0,0.2$ ) and $0.025 \%$ ( $\min , \max =0,0.2$ ), respectively. Virus diversity remained low in AG80 at week 18 (mean $=0.12$; $\min , \max =0,0.6$ ) and in AG46 at week $16($ mean $=0.26 ; \min , \max =0,0.6)$ (Figure 5).
Low diversity was also seen in macaques DL6V and DK40 that failed intermittent PrEP with two weekly doses of Truvada. Diversity of env sequences at peak viremia was $0.05 \%$ ( $\min , \max =0,0.2$ ) and $0.025 \%(\min , \max =0,0.2)$ for macaques DL6V and DK40, respectively, and remained low at week 15 in DL6V (mean $=0.12 ; \min , \max =0,0.5$ ), and at weeks 18 and 26 in DK40 (mean $=0.04$ ( $\min , \max =$ $0,0.3$ ) and 0.11 ( $\min , \max =0,0.5)$, respectively).

We also evaluated env nucleotide divergence from the transmitted founder viruses after 17 weeks in all 4 animals infected during PrEP (Figure 4). Mean nucleotide substitutions per site per year were $6.2 \times 10^{-3}\left(\mathrm{~min}, \max =5.8 \times 10^{-3}\right.$, $\left.8.7 \times 10^{-3}\right)$ for AG80, $7.6 \times 10^{-3}\left(\mathrm{~min}, \max =3.2 \times 10^{-3}\right.$, $9.8 \times 10^{-3}$ ) for AG46, $5.9 \times 10^{-3}\left(\mathrm{~min}, \max =0,1.2 \times 10^{-2}\right.$ ) for DK40, and $9.7 \times 10^{-3}\left(\mathrm{~min}, \max =3.5 \times 10^{-3}, 1.8 \times 10^{-2}\right.$ ) for DL6V.

The degree of env diversity and nucleotide divergence from the transmitted founder was compared between PrEP 


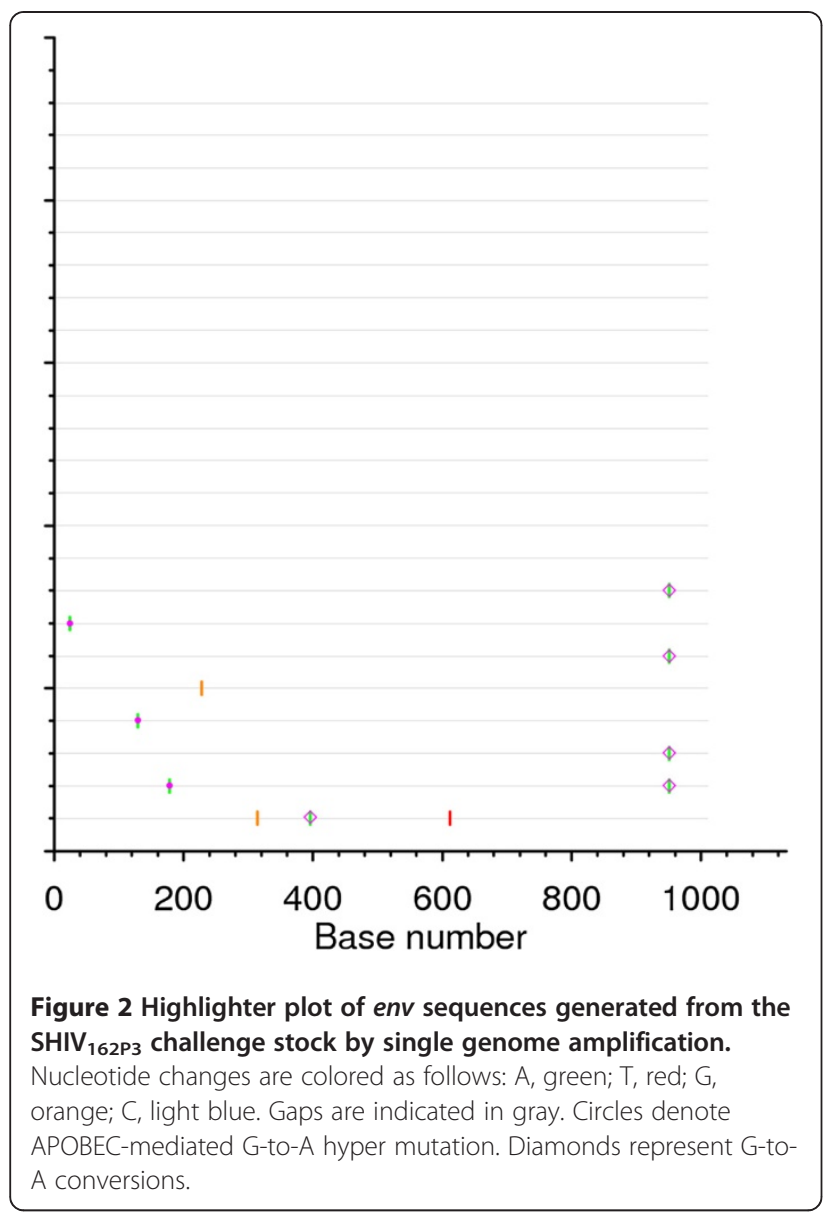

breakthrough and untreated control animals. To normalize for a similar follow up time, this analysis was limited to the first 17 weeks of infection (range $=12-20$ for controls and 15-18 for PrEP breakthroughs), and excluded the late time points that were only available in a few animals (24 weeks for AI22, and 26 weeks for AG94, $17 \mathrm{~V}$, and DK40). Over this 17 week period of time, the overall nucleotide divergence from transmitted founder viruses in the 4 PrEP breakthrough animals $\left(7.2 \times 10^{-3}\right.$; $\min , \max =5.9 \times 10^{-3}$, $9.7 \times 10^{-3}$ ) was significantly lower than in the five untreated control animals $\left(1.6 \times 10^{-2}\right.$; $\min , \max =3.7 \times 10^{-3}, 3.0 \times 10^{-2}$, $\mathrm{p}<0.0001$ ) (Figure 4). Table 1 shows that the overall env diversity in the 4 PrEP breakthrough infections was also significantly lower than that seen in the 5 untreated control macaques both at peak viremia and after 17 weeks of infection. The Neighbor-joining phylogenetic analysis of all 9 macaques and the $\mathrm{SHIV}_{162 \mathrm{P} 3}$ virus stock env sequences are shown in Figure 6 and illustrate how PrEP blunts the initial generation of virus diversity and diversification relative to untreated control animals.

\section{Amino acid mutations in variable regions of Env gp120}

To evaluate the effect of the observed nucleotide substitutions on Env protein evolution, we examined amino acid changes in the V1-V5 regions of consensus env sequences from all 9 macaques. No changes were observed in V1-V4 Env sequences from the four PrEP breakthroughs animals during the 15-26 weeks of follow up (Figure 7). Macaque DK40 had a single V451K change in V5, and macaque AG46 had a novel potential N-linked glycosylation site at position 453 of V5 (Figure 7). In contrast, 4 of the 5 untreated control macaques acquired multiple amino acid changes overtime in V1, V2, V3, or V5. At weeks 19 and 26 after peak viremia, untreated macaque AG94 acquired a novel potential $\mathrm{N}$-linked glycosylation site at position 129 $(\mathrm{H} 129 \mathrm{~N})$ in V1, N148D and D184N changes in V2, a P296H change in V3, and an R420K change in V5. Similarly, untreated macaque AI22 acquired the P296H change in V3 and the R420K/E change in V5 over time; macaque AO86 acquired an E421K change in V5, and macaque $17 \mathrm{~V}$ acquired N132D in V1, P296H in V3, and E421N in V5 (Figure 7). The Geno2pheno algorithm did not predict a change in co-receptor tropism associated with $\mathrm{P} 296 \mathrm{H}$ in V3. Control macaque AM20 did not acquire any amino acid changes in V1-V5 during this period of time (Figure 7).

\section{Discussion}

We used a macaque model of rectal SHIV transmission to explore the impact of PrEP on early virus evolution. Previously, we had found that SHIV infection of macaques during concurrent PrEP was characterized by $100-$ to $1000-$ fold lower peak viremias and a more rapid virus decline compared to untreated macaques [6-8]. It is unlikely that these low peak viremias are due to specific MHC-I genotypes since MHC-I alleles do not affect virus loads within the first few weeks of infection [17]. While MHC-I alleles and immune parameters can plausibly affect chronic phase viremias, the blunted acute viremias seen in our PrEP breakthrough animals likely reflect continuous ARV drug activity since PrEP regimens were maintained for 15 to 20 weeks after infection. Here, we demonstrate that such reduced acute viremias are associated with limited virus diversity and little or no env diversification during the first 20 to 30 weeks of infection. In contrast to viruses from 4 out of 5 untreated macaques that acquired multiple env mutations in V1-V5, we only found two amino acid changes in the V5 region from 2 of the 4 PrEP failures. ARV treatment during acute infection may substantially limit replication and/or select for variants with reduced RT function relative to wild type. These virological findings are consistent with earlier immunological studies in macaques that noted delayed maturation of antibody avidity and reduced inflammatory responses and early CD4+ T cell loss associated with PrEP use or acute ARV treatment $[6-10,18,19]$.

Our finding of limited viral evolution in the PrEP breakthrough animals may have important public health implications since early interactions between HIV and the host 


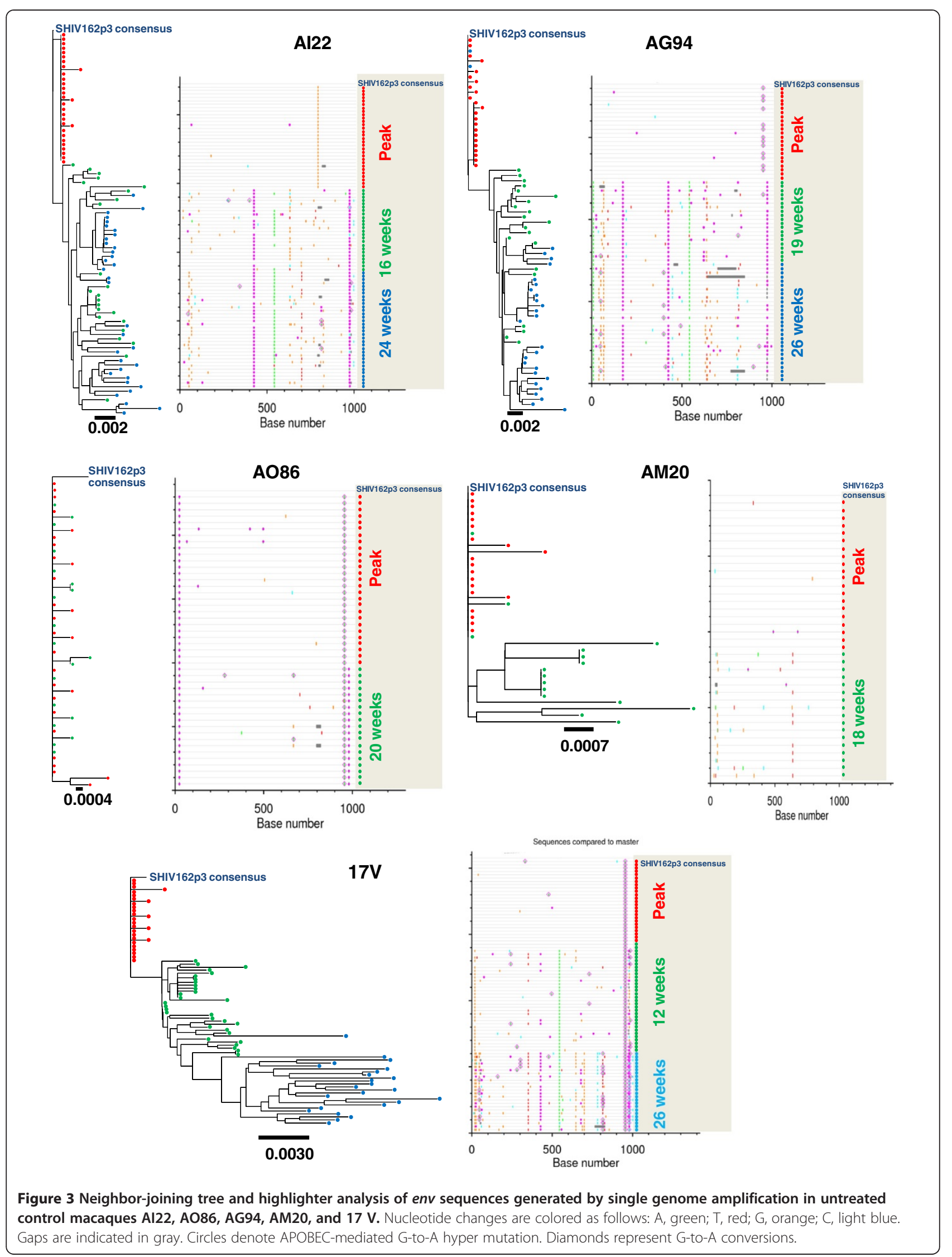




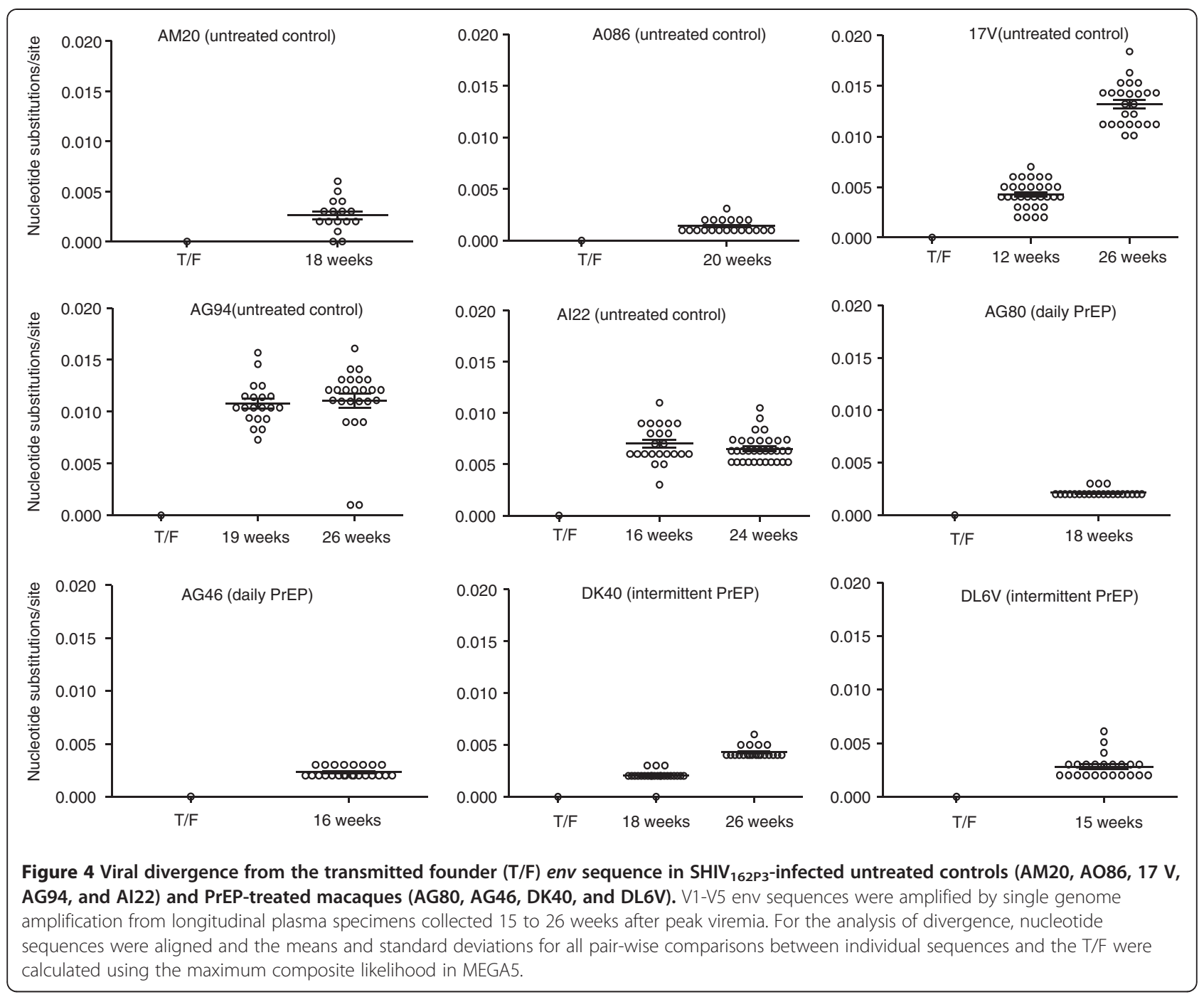

strongly influences pathogenesis and disease progression [20]. For instance, HIV-specific CD8+ T cell responses during primary infection are critical determinants for the subsequent control of viremia [21]. In HIV and SIV infections, the relatively homogeneous virus population seen at peak viremia subsequently undergoes significant evolution that rapidly increases the capacity to adapt to host immune responses [20]. A limited evolutionary potential associated with PrEP use may diminish the ability of HIV to escape host immune responses and enhance initial virus control. Limited virus evolution might also increase the window of vulnerability of HIV to vaccine-elicited immune responses as recently noted in vaccinated macaques receiving a sub-optimal dose of a topical microbicide [22].

The analysis of early env sequences from the five untreated macaques suggested that infection of these animals was initiated by a single founder virus, a finding that is consistent with the generally low multiplicity of infection associated with rectal infections in macaques and humans $[5,14,23]$. This observation is also consistent with the low $\left(10 \mathrm{TCID}_{50}\right)$ virus inoculum used to infect these animals and the limited heterogeneity of the SHIV $_{162 \mathrm{P} 3}$ virus stock [14,15]. A similar analysis suggested that infection in our animals receiving PrEP was also initiated by a single variant. However, estimation of the number of transmitted/founder variants in these PrEP breakthrough animals is difficult since continuous ARV drug activity might potentially favor monospecific expansions of viruses with fitness advantages in the presence of ARVs. Selection of these viruses would likely shape the virus population in the animals.

The alterations in early viral and immunological parameters seen in this and earlier studies are noteworthy and deserve careful consideration. Blunted acute viremias might conceivably reduce gut $\mathrm{CD} 4 \mathrm{~T}$ cell depletion, favor early restoration of mucosal $\mathrm{T}$ cells in the gut, and attenuate the course of infection [24]. However, our macaque model is not well suited to explore the long-term consequences of 


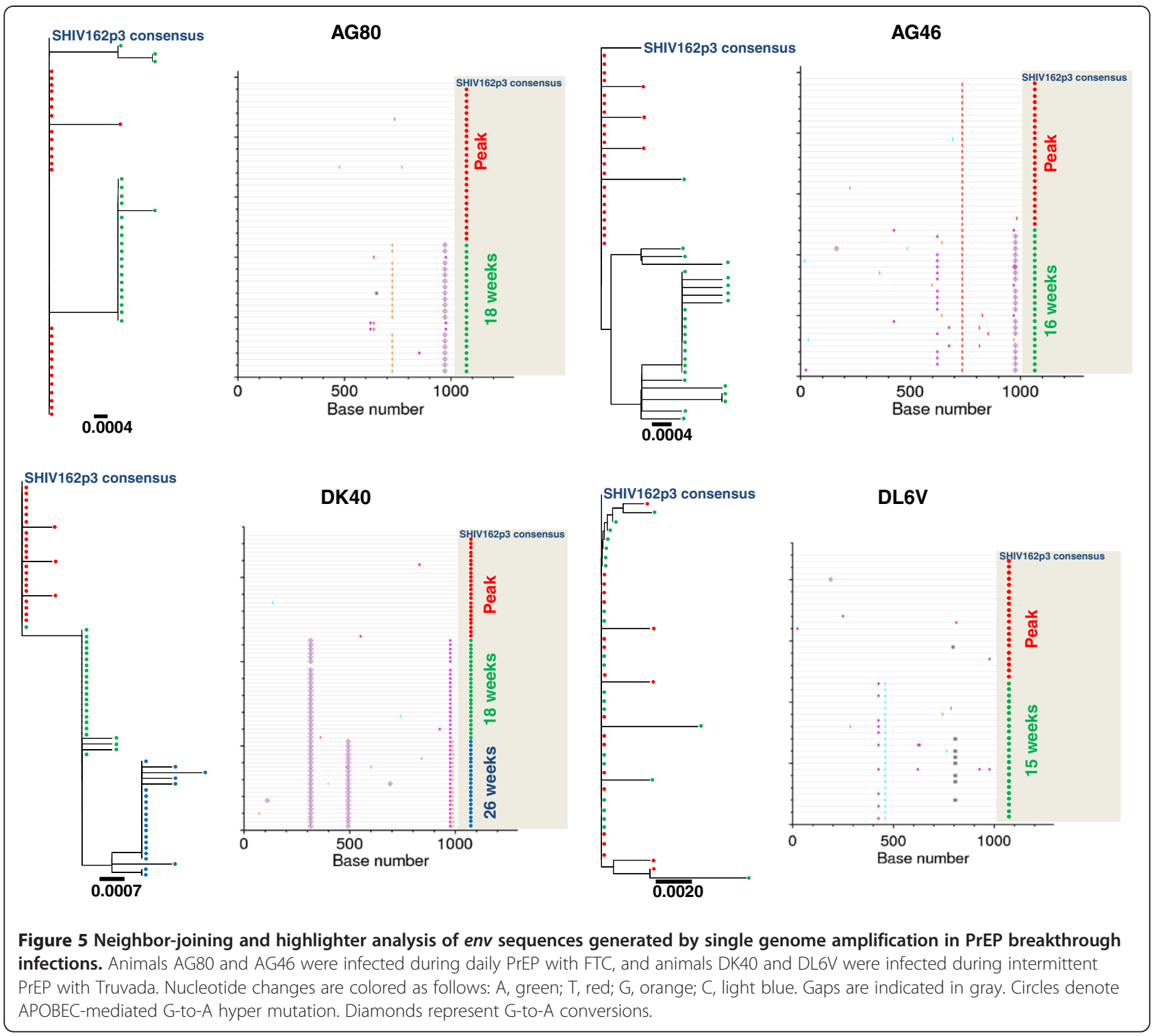

PrEP since we used a less pathogenic $\mathrm{SHIV}_{162 \mathrm{P} 3}$ isolate. $\mathrm{SHIV}_{162 \mathrm{P} 3}$ infections are characterized by early acute viremias similar to those seen in humans, but also low virus set points that generally result in a non-pathogenic disease course [25]. Unfortunately, the low set point viremias also preclude a more comprehensive analysis of viral evolution after PrEP discontinuation.

Table 1 SHIV $_{162 \mathrm{P} 3}$ env diversity in PrEP breakthroughs and untreated control macaques

\begin{tabular}{lccc}
\hline & \multicolumn{2}{c}{ Mean nucleotide diversity (\%) (range) } \\
& PrEP & Controls & P value \\
\hline Peak & $0.027(0.015-0.05)$ & $0.053(0.02-0.10)$ & $P<0.0001$ \\
Week 17* & $0.14(0.04-0.26)$ & $0.53(0.08-0.92)$ & $P<0.0001$ \\
\hline
\end{tabular}

* Sequences were obtained an average of 17 weeks post peak viremia for the 4 PrEP breakthroughs $(15,16,18$, and 18 weeks) and the 5 untreated controls $(12,16,18,19$, and 20 weeks).
In summary, we show in macaques that drug selective pressures associated with ARV use for PrEP significantly limit early virus replication and evolution, reinforcing the need to evaluate these parameters in humans. The impact of PrEP on early infection in humans is not known and will likely depend on both the extent of ARV drug exposure at the time of infection and prior to HIV diagnoses. This interval will typically be several weeks and might be sufficient to affect early virus evolution and immune responses. Careful analysis of the characteristics of HIV infections in highly adherent participants from ongoing clinical trials may help to clarify how PrEP use may impact early infection, risks for secondary transmission, and the rate of progression to HIV disease.

\section{Conclusions}

We explored in macaques the impact of PrEP on early viral dynamics and evolution. We demonstrate for the first time 


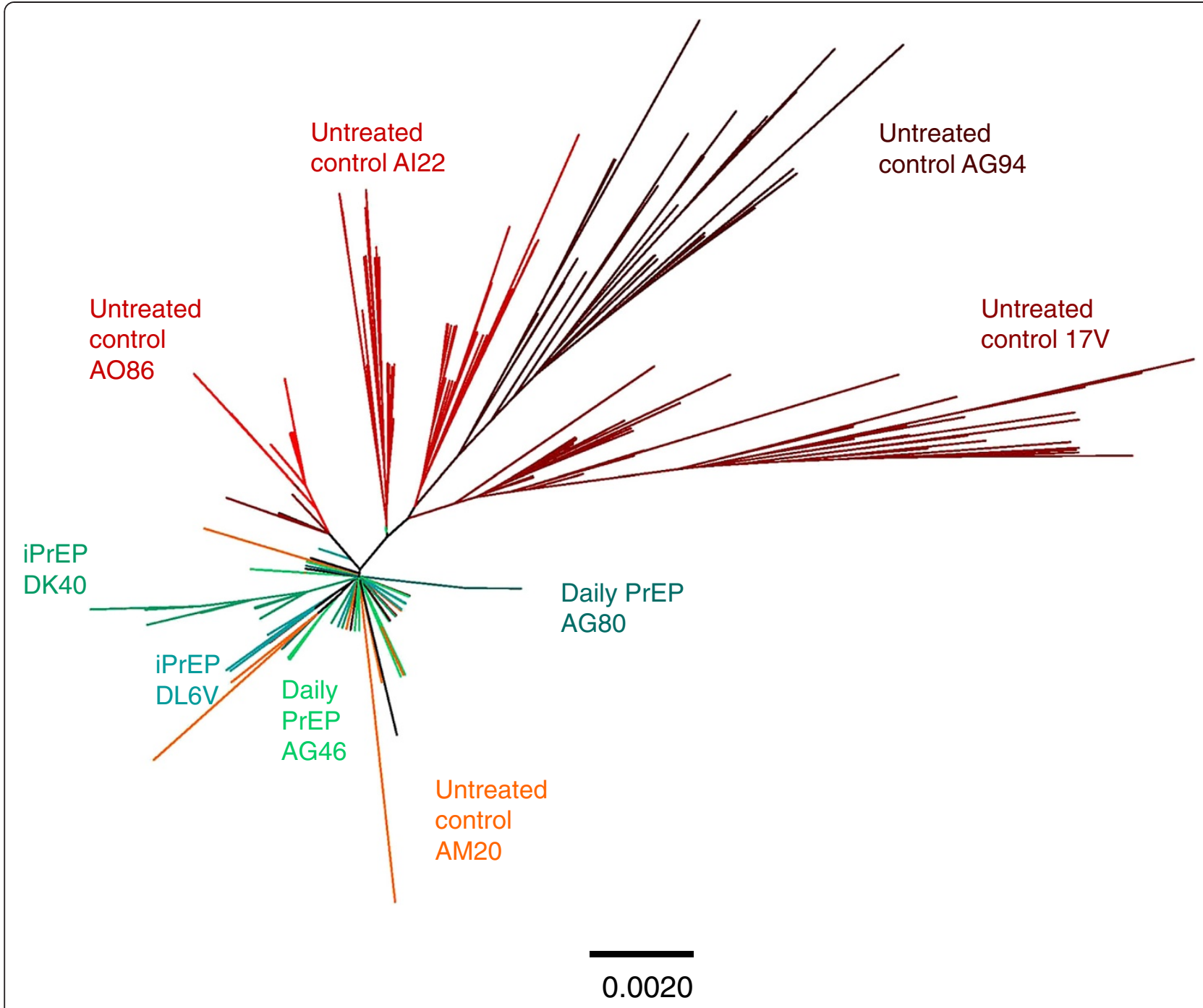

Figure 6 Phylogenetic analysis of $\mathrm{SHIV}_{162 \mathrm{P} 3}$ challenge stock and longitudinal env sequences generated by single genome amplification in all six infected macaques. The neighbor-joining method was used for the analysis. V1-V5 env sequences from individual macaques are color coded. PrEP breakthrough infections are characterized by a reduced generation of virus diversity relative to untreated animals as evidenced by the length of the branches.

that PrEP significantly halts early virus evolution by containing the initial explosion of virus replication and diversification. These virological findings complement earlier immunological studies in macaques that noted altered immune responses associated with PrEP. Our findings emphasize the need to understand the characteristics of $\mathrm{HIV}$ infections that occur during PrEP implementation in humans.

\section{Methods}

\section{Macaques and experimental SHIV infection}

A total of nine male Indian rhesus macaques infected rectally with $\mathrm{SHIV}_{162 \mathrm{P} 3}$ were studied. $\mathrm{SHIV}_{162 \mathrm{P} 3}$ is a chimeric virus that contains the tat, rev, and env coding regions of
HIV-1SF162 in a SIVmac239 background (National Institutes of Health AIDS Research and Reference Reagent Program [26]). All animals became infected during repeated weekly non-traumatic exposures to a low dose $\left(10 \mathrm{TCID}_{50}\right)$ of $\mathrm{SHIV}_{162 \mathrm{P3}}$ as previously described [7,8]. Macaques AG80 and AG46 received daily PrEP with human-equivalent doses of FTC $(20 \mathrm{mg} / \mathrm{kg})$ and became infected after 5 and 10 rectal exposures, respectively. Macaques DK40 and DL6V received intermittent PrEP with 2 weekly human-equivalent doses of Truvada (22 mg/kg TDF and $20 \mathrm{mg} / \mathrm{kg}$ FTC) and became infected after 2 and 4 rectal challenges, respectively $(6,7)$. Macaques AM20, 17 V, AO86, AI22, and AG94 are untreated control animals that did not receive PrEP and became infected after $3,1,1,5$ and 3 rectal exposures, 


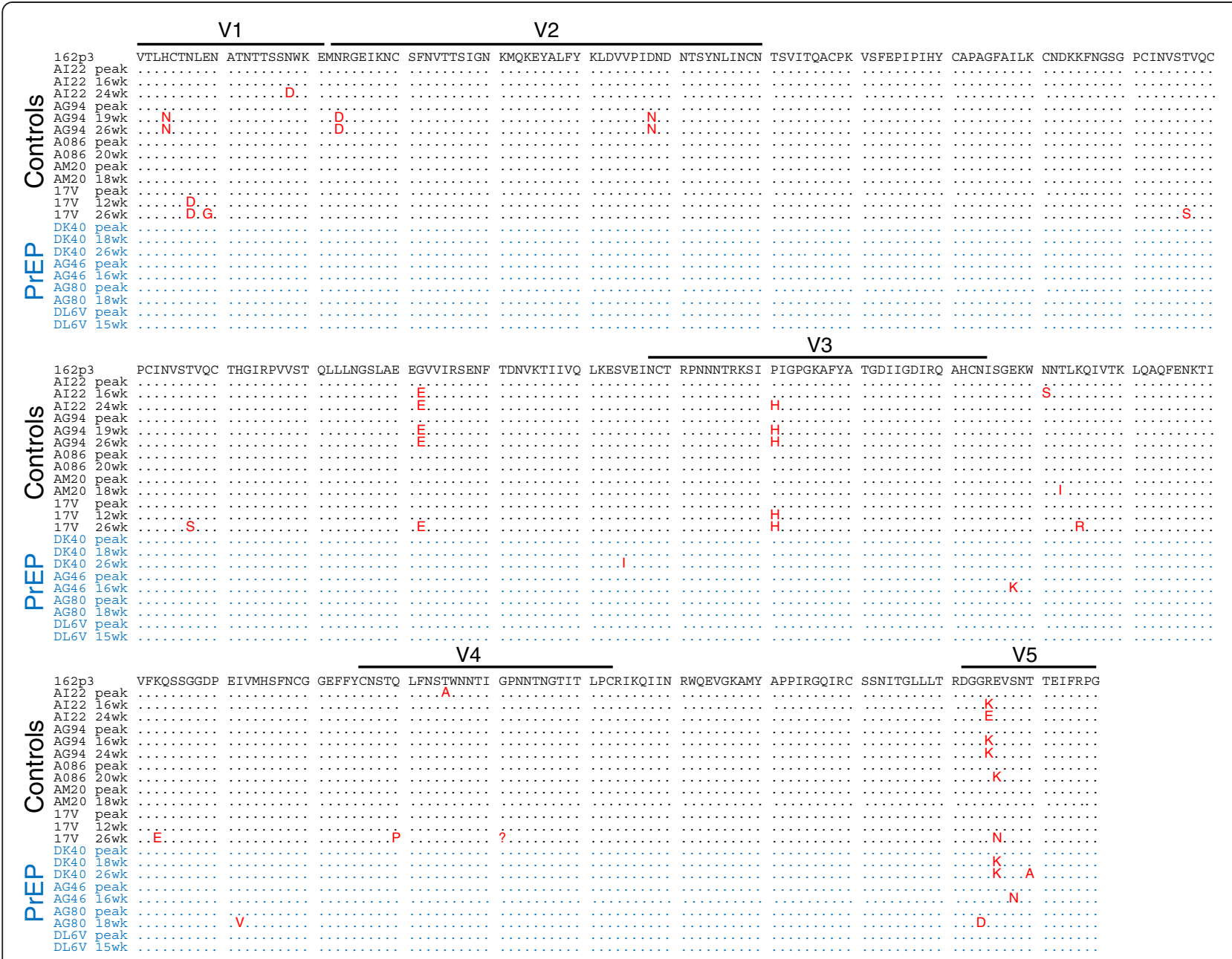

Figure 7 Consensus Env V1-V5 amino acid sequences generated by single genome amplification in longitudinal specimens from untreated and PrEP breakthrough animals. Sequences are aligned with a reference SHIV ${ }_{162 \text { P3 } 3}$ isolate (GenBank accession number AF536757). Amino acid changes in gp120 are shown for each animal.

respectively [7,8] (Figure 1). The Institutional Animal Care and Use Committee of the Centers for Disease Control and Prevention approved these studies.

\section{Viral RNA extraction and CDNA generation}

Viral RNA was extracted from longitudinal plasma specimens collected from macaques AG80, AG46, DK40, DL6V, AM20, 17 V, AO86, AG94 and AI22 at peak viremia and during 17 to 29 weeks of follow up using the QIAmp Viral RNA Mini Kit (Qiagen) (Figure 1). Specimens were selected based on detectable RNA in plasma by RT-PCR $[7,8]$. CDNA was generated by reverse transcription using primer QZR2 (5' ACA GCT CCT AGC GTC ACT GCT C 3') and Superscript III reverse transcriptase (RT) according to the manufacturer's instructions (Invitrogen, Carlsbad, California). Briefly, $30 \mu \mathrm{l}$ of plasma RNA were added to an RT cocktail containing $1.5 \mu \mathrm{l}$ of primer QZR2 $(10 \mu \mathrm{M}), 3 \mu \mathrm{l}$
dNTPs $(10 \mathrm{mM}), 3 \mu \mathrm{l}$ DTT (100 mM), RNase OUT (120 units), and 600 units of Superscript III RT (Invitrogen) for a total $60 \mu \mathrm{l}$ reaction. Reverse transcription was done at $50^{\circ} \mathrm{C}$ for 60 minutes and $55^{\circ} \mathrm{C}$ for 60 minutes. The mixture was heat inactivated at $70^{\circ} \mathrm{C}$ for 15 minutes and then treated with RNase $\mathrm{H}$ for 20 minutes at $37^{\circ} \mathrm{C}$ to remove the RNA template.

\section{Single genome amplification (SGA)}

$1.105 \mathrm{~kb}$ env sequences containing the V1-V5 region of gp120 (nucleotide positions 348 to 1,453 relative to HIV-1 isolate SF162, GenBank accession number EU123924) were generated by SGA. Briefly, serial dilutions of the RTgenerated cDNA were made in 96-well plates to identify dilutions resulting in $<30 \%$ of positive wells. Based on a Poisson distribution, amplifications at this dilution represent sequences derived from a single cDNA copy [11]. PCR 
reactions were done using $2 \mu \mathrm{l}$ of cDNA at the appropriate dilution and a PCR cocktail containing primer QZF3 (5' CCC ACA GAC CCT AAC CCA CAA GA 3') and QZR2. The mixture was incubated for 2 minutes at $94^{\circ} \mathrm{C}$ followed by 40 cycles of $15 \mathrm{~s}$ at $94^{\circ} \mathrm{C}, 30 \mathrm{~s}$ at $54^{\circ} \mathrm{C}, 90 \mathrm{~s}$ at $68^{\circ} \mathrm{C}$, and a final extension of 15 minutes at $68^{\circ} \mathrm{C}$. A $2-\mu \mathrm{l}$ volume was then used for a nested PCR reaction using primers QZF4 (5' GCC ATG TGT AAA GTT AAC CCC ACT C 3') and QZR3 (5' GCC TTG GTG GGT GCT ACT CCT A 3') and 45 cycles of $15 \mathrm{~s}$ at $94^{\circ} \mathrm{C}, 30 \mathrm{~s}$ at $54^{\circ} \mathrm{C}, 60 \mathrm{~s}$ at $68^{\circ} \mathrm{C}$, with a final extension of 15 minutes at $68^{\circ} \mathrm{C}$. Nested-PCR products were visualized using a pre-cast 96 -well $1 \%$ agarose gel system and the E-Editor software tool (Invitrogen, Carlsbad, California). The number of positive wells was computed to ensure an amplification rate lower than $30 \%$. Positive PCR products were then purified for subsequent sequence analysis using the Quick PCR purification kit (Qiagen).

\section{Sequence analysis}

Env sequences were obtained using an ABI3130xl automated sequencer with primers QZR3, QZR5 (5' GGT CCC CTC CTG AGG ATT GCT TA 3'), QZF7 (5' CAG TCT AGC AGA AGA AGG GGT AG 3'), QZF5 (5' CAC AAG CCT GTC CAA AGG TAT CC 3', QZR6 (5' GCT TTC CCC GGT CCT ATA GGT A 3'), and QZF8 (5' TAC CTA TAG GAC CGG GGA AAG C $3^{\prime}$ ). PCR conditions included 25 cycles of $10 \mathrm{~s}$ at $96^{\circ} \mathrm{C}$ and $10 \mathrm{~s}$ at $55^{\circ} \mathrm{C}$. The Vector NTI Advance program (version 11.5.0) was used to analyze the data and to infer amino acid sequences.

Phylogenetic analysis was done using the MEGA (version 5.0) software package. The Hasegawa, Kishino, and Yano model with gamma distributed rates and a proportion of invariable sites was inferred to be the best model of nucleotide substitution for env sequences from each individual animal, the SHIV inoculum, and all sequences combined by using maximum likelihood (ML) best fit analysis in the MEGA program. Nucleotide alignments were prepared using Clustal W in MEGA. All indels were manually removed from the alignments prior to phylogenetic analysis. Phylogenetic trees were inferred using neighbor joining (NJ) and ML methods and rooted with the $\mathrm{SHIV}_{162 \mathrm{P} 3}$ env consensus sequence. Viral diversity was inferred by analysis of neighbor-joining trees and the Highlighter tool available at http://www.hiv.lanl. gov/content/sequence/HIGHLIGHT/highlighter.html.

The number of transmitted/founder variants that established infection was determined by exploring the pattern of env diversity at peak viremia. For this analysis, we excluded hyper mutated sequences and gaps, and assumed that variants with two or less unique nucleotide changes arise from the same transmitted founder virus [11]. Estimates of evolutionary divergence were done by pairwise analysis of individual sequences and the transmitted/founder virus using the maximum composite likelihood method in MEGA5, and results are expressed as number of nucleotide substitutions per site per year $[27,28]$. Mean nucleotide diversity and divergence for PrEP breakthrough animals and controls were compared by using a two-tailed t test (GraphPad Prism, version 5.04). Tropism was evaluated using the geno2pheno co-receptor tool (Version 2.0) available at http:// coreceptor.bioinf.mpi-inf.mpg.de/index.php following the recommendations from the European Consensus Group. Potential N-linked glycosylation sites were analyzed using the N-GlycoSite tool available at http://www.hiv. lanl.gov/content/sequence/GLYCOSITE/glycosite.html.

\section{Abbreviations}

PrEP: Pre-exposure prophylaxis; SGA: Single genome amplification; FTC: Emtricitabine; TDF: Tenofovir disoproxil fumarate.

\section{Competing interests}

The authors declare that they have no competing interests.

\section{Acknowledgements}

We gratefully thank Priya Srinivasan and Dr. James Smith for their technical assistance with procedures for single genome amplification, Anupama Shankar for her valuable help with the analysis of env sequences, and Dr. Richard Haaland for critical review of this manuscript and helpful input.

\section{Authors' contributions}

QZ and SR carried out the molecular genetic studies and phylogenetic analysis. BS participated in the analysis and interpretation of data and helped to draft the manuscript. WH participated in the study design and helped to draft the manuscript. JGG-L conceived and coordinated the study and drafted the manuscript. All authors read and approved the final manuscript.

\section{Disclaimer}

The findings and conclusions in this report are those of the authors and do not necessarily represent the views of the Centers for Disease Control and Prevention.

\section{Funding}

This work was partially supported by Interagency Agreement Y1-Al-0681-02 between $\mathrm{CDC}$ and $\mathrm{NIH}$.

Received: 14 October 2011 Accepted: 9 May 2012 Published: 9 May 2012

\section{References}

1. García-Lerma JG, Paxton L, Kilmarx P, Heneine W: Oral pre-exposure prophylaxis for HIV prevention. Trends Pharmacol Sci 2010, 31:74-81.

2. Thigpen MC, Kebaabetswe PM, Smith DK, Segolodi TM, Soud FA, Chillag K, Chirwa LI, Kasonde M, Mutanhaurwa R, Henderson FL, Pathak S, Gvetadze R, Rose CE, Paxton LA: Daily oral antiretroviral use for the prevention of HIV infection in heterosexually active young adults in Botswana: results from the TDF2 study. Rome: International AIDS Society meeting; 2011.

3. Grant RM, Lama JR, Anderson PL, McMahan V, Liu AY, Vargas L, Goicochea P, Casapía M, Guanira-Carranza JV, Ramirez-Cardich ME, Montoya-Herrera O, Fernández T, Veloso VG, Buchbinder SP, Chariyalertsak S, Schechter M, Bekker LG, Mayer KH, Kallás EG, Amico KR, Mulligan K, Bushman LR, Hance RJ, Ganoza C, Defechereux P, Postle B, Wang F, McConnell JJ, Zheng JH, Lee J, Rooney JF, Jaffe HS, Martinez Al, Burns DN, Glidden DV, iPrEx Study Team: Preexposure chemoprophylaxis for HIV prevention in men who have sex with men. N Engl J Med 2010, 363:2587-2599.

4. Baeten J: Antiretroviral Pre-Exposure Prophylaxis for HIV-1 prevention among heterosexual African men and women: the Partners PrEP Study. Rome: International AIDS Society meeting; 2011.

5. Varela M, Landskron L, Lai RP, McKinley TJ, Bogers WM, Verschoor EJ, Dubbes R, Barnett SW, Frost SD, Heeney JL: Molecular evolution analysis of 
the human immunodeficiency virus type 1 envelope in simian/human immunodeficiency virus-infected macaques: implications for challenge dose selection. J Virol 2011, 85:10332-10345.

6. García-Lerma JG, Aung W, Cong ME, Zheng Q, Youngpairoj AS, Mitchell J, Holder A, Martin A, Kuklenyik S, Luo W, Lin CY, Hanson DL, Kersh E, Pau CP, Ray AS, Rooney JF, Lee WA, Heneine W: Natural substrate concentrations can modulate the prophylactic erfficacy of nucleotide HIV reverse transcriptase inhibitors. J Virol 2011, 85:6610-6617.

7. García-Lerma JG, Cong M, Mitchell J, Youngpairoj AS, Zheng Q, Masciotra S, Martin A, Kuklenyik Z, Holder A, Lipscomnb J, et al: Intermittent prophylaxis with oral truvada protects macques form rectal SHIV infection. Sci Transl Med 2010, 2:14ra14.

8. García-Lerma JG, Otten RA, Qari SH, Jackson E, Cong M, Masciotra S, Luo W, Kim C, Adams DR, Monsour M, et al: Prevention of rectal SHIV transmission in macaques by daily or intermittent prophylaxis with emtricitabine and tenofovir. PLoS Med 2008, 5:e28.

9. Curtis KA, Kennedy MS, Luckay A, Cong ME, Youngpairoj AS, Zheng Q, Smith J, Hanson D, Heneine W, Owen SM, García-Lerma JG: Delayed maturation of antibody avidity but not seroconversion in Rhesus macaques infected with SHIV during oral pre-exposure prophylaxis. J Acquir Immune Defic Syndr 2011, 57:355-362.

10. Kersh EN, Luo W, Zheng Q, Adams DR, Youngpairoj A, Cong M, McNicholl J, Hendry M, Heneine W, Garcia-Lerma JG: Oral PrEP during mucosal SHIV infection reduces viremia, preserves CD4 counts, and raises potent $\mathrm{T}$ cell responses. 18th International AIDS conference 2010, Vienna, Austria Oral presentation at symposium "Understanding HIV Transmission Mechanisms: Microbicides and PrEP" 2010,

11. Salazar-Gonzalez JF, Bailes E, Pham KT, Salazar MG, Guffey MB, Keele BF, Derdeyn CA, Farmer P, Hunter E, Allen S, Manigart O, Mulenga J, Anderson JA, Swanstrom R, Haynes BF, Athreya GS, Korber BT, Sharp PM, Shaw GM, Hahn BH: Deciphering human immunodeficiency virus type 1 transmission and early envelope diversification by single-genome amplification and sequencing. J Virol 2008, 82:3952-3970.

12. Palmer S, Kearney M, Maldarelli F, Halvas EK, Bixby CJ, Bazmi H, Rock D, Falloon J, Davey RT Jr, Dewar RL, Metcalf JA, Hammer S, Mellors JW, Coffin JM: Multiple, linked human immunodeficiency virus type 1 drug resistance mutations in treatment-experienced patients are missed by standard genotype analysis. J Clin Microbiol 2005, 43:406-413.

13. Keele BF, Giorgi EE, Salazar-Gonzalez JF, Decker JM, Pham KT, Salazar MG, Sun C, Grayson T, Wang S, Li H, et al: Identification and characterization of transmitted and early founder virus envelopes in primary HIV-1 infection. Proc Natl Acad Sci U S A 2008, 105:7552-7557.

14. Liu J, Keele BF, Li H, Keating S, Norris PJ, Carville A, Mansfield KG, Tomaras GD, Haynes BF, Kolodkin-Gal D, Letvin NL, Hahn BH, Shaw GM, Barouch DH: Low-dose mucosal simian immunodeficiency virus infection restricts early replication kinetics and transmitted virus variants in rhesus monkeys. J Virol 2010, 84:10406-10412.

15. Smith JM, Dauner A, Li B, Srinivasan P, Mitchell J, Hendry M, Ellenberger D, Butera S, Otten RA: Generation of a dual RT Env SHIV that is infectious in rhesus macaques. J Med Primatol 2010, 39:213-223.

16. Stone M, Keele BF, Ma ZM, Bailes E, Dutra J, Hahn BH, Shaw GM, Miller CJ: A limited number of simian immunodeficiency virus (SIV) env variants are transmitted to rhesus macaques vaginally inoculated with SIVmac251. J Virol 2010, 84:7083-7095.

17. Loffredo JT, Maxwell J, Qi Y, Glidden CE, Borchardt GJ, Soma T, Bean AT, Beal DR, Wilson NA, Rehrauer WM, Lifson JD, Carrington M, Watkins DI: Mamu$B^{*} 08$-positive macaques control simian immunodeficiency virus replication. J Virol 2007, 81:8827-8832.

18. van Rompay KK, Dailey PJ, Tarara RP, Canfield DR, Aguirre NL, Cherrington JM, Lamy PD, Bischofberger N, Pedersen NC, Marthas ML: Early short-term 9-[2-(R)-(phosphonomethoxy)propyl]adenine treatment favorably alters the subsequent disease course in simian immunodeficiency virus-infected newborn Rhesus macaques. J Virol 1999, 73:2947-2955.

19. Watson A, McClure J, Ranchalis J, Scheibel M, Schmidt A, Kennedy B, Morton WR, Haigwood NL, Hu SL: Early postinfection antiviral treatment reduces viral load and prevents CD4+ cell decline in HIV type 2-infected macaques. AIDS Res Hum Retroviruses 1997, 13:1375-1381.

20. Boutwell CL, Rolland MM, Herbeck JT, Mullins Jl, Allen TM: Viral evolution and escape during acute HIV-1 infection. J Infect Dis 2010, 202:S309-S314.

21. Streeck H, Jolin JS, Qi Y, Yassine-Diab B, Johnson RC, Kwon DS, Addo MM, Brumme C, Routy JP, Little S, Jessen HK, Kelleher AD, Hecht FM, Sekaly RP, Rosenberg ES, Walker BD, Carrington M, Altfeld M: Human immunodeficiency virus type 1-specific CD8+ T-cell responses during primary infection are major determinants of the viral set point and loss of CD4+ T cells. J Virol 2009, 83:7641-7648.

22. Cheng-Mayer C, Huang Y, Gettie A, Tsai L, Ren W, Shakirzyanova M, Sina ST, Trunova N, Blanchard J, Jenkins LM, Lo Y, Schito ML, Appella E: Delay of SHIV infection and control of viral replication in vaccinated macaques challenged in the presence of a topical microbicide. AIDS 2011, 25:1833-18841.

23. Li H, Bar KJ, Wang S, Decker JM, Chen Y, Sun C, Salazar-Gonzalez JF, Salazar MG, Learn GH, Morgan CJ, Schumacher JE, Hraber P, Giorgi EE, Bhattacharya T, Korber BT, Perelson AS, Eron JJ, Cohen MS, Hicks CB, Haynes BF, Markowitz M, Keele BF, Hahn BH, Shaw GM: High multiplicity infection by HIV-1 in men who have sex with men. PLoS Pathog 2010, 6:e1000890.

24. Mehandru S, Poles MA, Tenner-Racz K, Manuelli V, Jean-Pierre P, Lopez $P$, Shet A, Low A, Mohri H, Boden D, Racz P, Markowitz M: Mechanisms of gastrointestinal CD4+ T-cell depletion during acute and early human immunodeficiency virus type 1 infection. J Virol 2007, 81:599-612.

25. Harouse JM, Gettie A, Eshetu T, Tan RC, Bohm R, Blanchard J, Baskin G, Cheng-Mayer C: Mucosal transmission and induction of simian AIDS by CCR5-specific simian/human immunodeficiency virus SHIV(SF162P3). J Virol 2001, 75:1990-1995.

26. Harouse JM, Gettie A, Tan RC, Blanchard J, Cheng-Mayer C: Distinct pathogenic sequela in rhesus macaques infected with CCR5 or CXCR4 utilizing SHIVs. Science 1999, 284:816-819.

27. Tamura K, Nei M, Kumar S: Prospects for inferring very large phylogenies by using the neighbor-joining method. Proc Natl Acad Sci U S A 2004, 101:11030-11035

28. Tamura K, Dudley J, Nei M, Kumar S: MEGA4: Molecular Evolutionary Genetics Analysis (MEGA) software version 4.0. Mol Biol Evol 2007, 24:1596-1599.

doi:10.1186/1742-4690-9-40

Cite this article as: Zheng et al:: Limited SHIV env diversification in macaques failing oral antiretroviral pre-exposure prophylaxis. Retrovirology 2012 9:40.

\section{Submit your next manuscript to BioMed Central and take full advantage of:}

- Convenient online submission

- Thorough peer review

- No space constraints or color figure charges

- Immediate publication on acceptance

- Inclusion in PubMed, CAS, Scopus and Google Scholar

- Research which is freely available for redistribution 